which Professor Gamgee operated for me at the Albert Veterinary College, and the superiority of the silk was manifest. But what we have to look to is the effect on the tissues strangulated, rather than the material by which the strangulation is effected. If anything like what goes on outside the body when the clamp is used, or inside when the wound is left open for ligatures, were to go on when the wound is closed, it is difficult to understand how any patient could possibly survive the process. She would almost infallibly be poisoned by absorption of the footid products of the decomposing stump. But a very different series of changes must go on when the wound is closed and access of air is shut off. At any rate, experience proves that patients do survive the process; and post mortem examination has shown that ligature and pedicle have been coated by a sort of capsule of lymph. In my own hands, this practice has been much less successful than the clamp; and, even when patients have recovered, some of them have long remained in a state of semi-invalidism, very different from the robust health which is the rule after successful clamp-cases. This plan is that always followed by Dr. Tyler Smith. It was originated in 1821 , by Dr. Nathan Smith of Baltimore, who used leather ligatures. Dr. Rogers of New York, in 1830, also cut off his ligatures "close to the knot, and left them to absorption." If I use the ligature, I feel disposed to cut off the ends whenever the patient is in pretty good condition, and sthenic peritonitis with effusion of lymph may be expected; but if low diffuse peritonitis and effusion of serum may be feared, then I suspect it would be better to leave the ends of the ligatures, and secure a drain through the wound for the serum. But we should still search for a better method than the ligature.

The écraseur I used once, and successfully. But I have not ventured on it again; for, if it should prove untrustworthy, and internal bleeding occur in any case, one's self-reproach would be very painful.

The cautery alone would almost certainly fail to stop such large vessels as are frequently met with in a pedicle. So might the écraseur alone, or the crushing which precedes division by the écraseur. But the combination of crushing and the cautery is certainly efficacious in a considerable proportion of cases. Mr. Clay of Birmingham, as I said just now, introduced the practice, and carried it o.t by his "adhesive clam" and hot irons. I wrote to him at the time, that, if it answered for adhesions and omentum, it ought to answer for the pedicle. And I might have tried it; but my first trial on a piece of omentum was unsuccessful, and I did not repeat it. But latterly Mr. Baker Brown has published so many cases in which he has successfully secured the pedicle on Mr. Clay's principle of combining pressure with the cautery, that I have tried it in five cases. Three of the patients recovered, and two died. In three, the cautery was alone sufficient to stop all bleeding. Two of these patients recovered, and one died. In two others, on opening the clamp, considerable vessels bled, and ligatures had to be applied. One of them recovered, and the other died. I shew you here Mr. Clay's "clam", and the instrument as modified by $\mathrm{Mr}$. Brown. It will be for further experience to determine whether, in cases of short pedicle, the ligature with the ends cut off short, or the écraseur, or the combination of crushing and cauterisation, is the more successful practice. For a long pedicle, I still prefer the clamp. It has been used before you in two cases, and you will hear the result. I feel very hopeful that it will be favourable in both cases; for Dr. Waters, as well as the surgeons, Messrs. Brittain and Weaver, to whom you are indebted for the opportanity of witnessing this operation, still new in many of our hospitals, have done everything in their power to insure success-have placed separate rooms at the disposal of the house-surgeon, Mr. Karkeek, who will add his earnest and hearty endeavours in a good cause; and, with such pure air to assist us as we sadly want in smoky London, and which comes here direct from the Welsh hills which you see from the windows, I trust the attempt to save the lives of the two women will prove creditable to surgery.

[ERratum. In last week's number, page 353, column 1, line 49, for "parietal cavity", read "peritoneal cavity".]

\section{Crawsactions of a}

\author{
SOUTH-EASTERN BRANCH.
}

CASES IN THE PRACTICE OF MEDICINE.

By John Richard Wardeli, M.D., M.R.C.P., Physician to the Tunbridge Wells Infirmary.

$$
\text { [Read June 14th, 1866.] }
$$

Berng aware that the general business of this our annual meeting must necessarily consume much of the short time at our disposal, and as other gentlemen will read communications, I shall not trespass upon your patience by reading a prolix paper. I have therefore selected three examples of disease from my case-book, which are of a practical character, and the chief features of which I shall detail as concisely as possible. The first of these is one of very uncommon description ; it is that of

Acute Peritonitis and Displacement of the Cocum. J. E., agred 37, a muscular, well made man, who was employed as a driver of railway wagons, in the construction of the Brighton and Tunbridge Wells Railway, was admitted into the Infirmary on Saturday evening, April 8th, 1865. On admission, he was in a state of great prostration. The abdomen was dis. tended; and he complained, as he expressed himself, of much pain in the bowels. He had been under the care of Mr. Wallis at Hartfield; and that gentleman believed that from some cause there was obstruction in the bowels. Purgatives had been given without effect; and the bowels had not been moved since the previous Wednesday. He reported that sickness and vomiting had followed the administration of the purgatives; but from the man's account the ejected matters had been merely of the ordinary bilious character.

I saw him for the first time on Monday morning, April 10th. He then lay on his back, with his knees slightly elevated, in a state of great prostration; the features were sharp and sunken; the surface bedewed with a clammy sweat; the extremities were of low temperature; the breathing thoracic; the pulse was small, compressible, and 130 ; the tongue was moist, and he complained of thirst. The physical signs of the thorax, so far as could be ascertained from anterior examination, were normal. The abdomen was distended and tympanitic; and there was diffused tenderness on moderate pressure, but palpation discovered most pain at the left hypogastric and left iliac regions. A few red suspicious puncta were seen on the abdomen. He said he had been at work up to April 4th, but for some days prior to that date had felt "weary and weak." On the 3rd and 4th, he had pains in the limbs, shivering, and headache; and diarrhœa then came on, the stools being of ochrey colour. He attributed his illness to indulgence in bad porter. During the two nights of his residence 